\title{
Citizens Safe Mobility Necessitate the Implementation of a Primary Health Care E-Gov Service: The Case of The Europeans
}

\author{
Alexander B Sideridis ${ }^{1 *}$ and Loucas Protopappas ${ }^{2}$ \\ ${ }^{1}$ Informatics Lab, AUA, Athens, Greece \\ ${ }^{2}$ Agricultural University of Athens, Greece \\ *Corresponding author: Alexander B Sideridis, Agricultural University of Athens, Greece
}

\begin{tabular}{|c|c|}
\hline ARTICLE INFO & ABSTRACT \\
\hline Received: 輩 January 19, 2021 & $\begin{array}{l}\text { Citation: Alexander B Sideridis, Loucas Protopappas. Citizens Safe Mobility Necessitate } \\
\text { the Implementation of a Primary Health Care E-Gov Service: The Case of The Europeans. }\end{array}$ \\
\hline Published: 慧 January 28, 2021 & Biomed J Sci \& Tech Res 33(3)-2021. BJSTR. MS.ID.005408. \\
\hline
\end{tabular}

\section{Introduction}

The design of network infrastructure of Primary Health Care centres is aiming to provide medical services to citizens in mobility, for example citizens of the European Union moving from a Member State (MS) A to a MS B. Health care authorized personnel have immediate and direct access to medical files kept by the National Health system of these people (Figure 1). Smart Cross Border e-Gov Systems and Cloud Computing [1,2] seem to form the appropriate modules capable to support such services and alleviate any interoperability, authenticity and safety of sensitive i

nformation issues that usually occur with such operations $[2,3]$. Medical history, diagnostic tests and various medical documents when and if required by qualified actors of any authorized medical service provider, after well certified authentication process, should be available online. Recently, has been proposed a system providing such a service. Its architecture is that of a Smart Cross Border e-Gov model [1,2] and it actually integrates a Decision Support System consisting of three structural blocks. The I/O, the ValidationAuthentication-Identification (VAI) and Processing blocks [3].

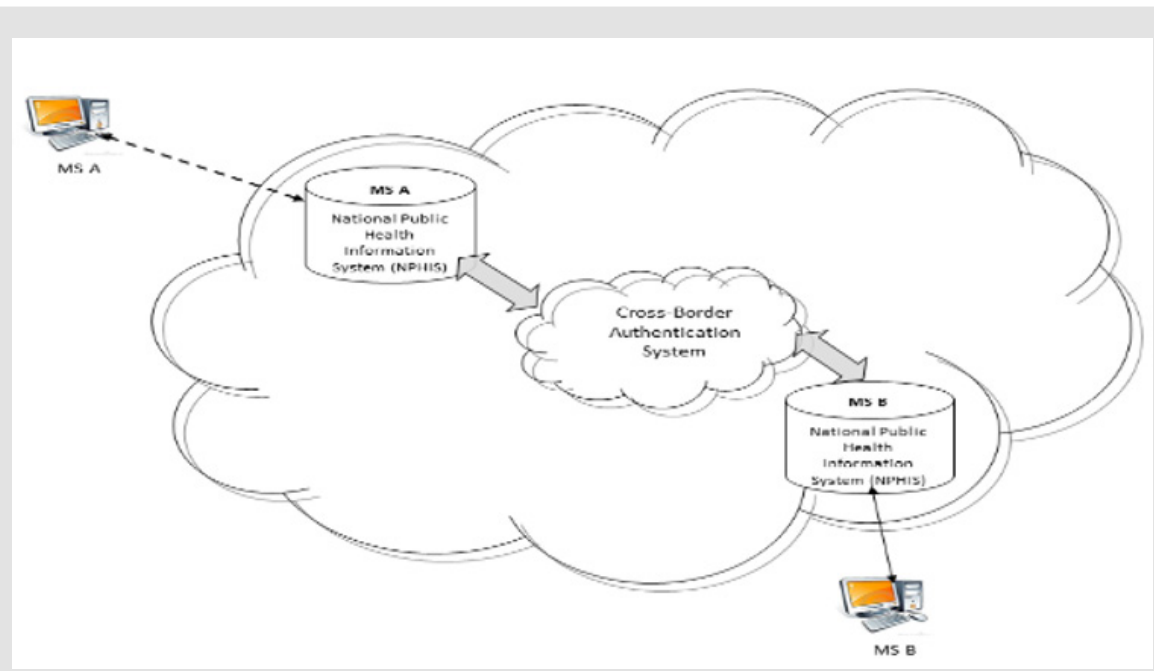

Figure 1: Medical File Authentication Process in Primary Health Care Services. 
An essential part of the above system consists of the platforms developed by STORK 2.0. project $[3,4]$ as these platforms include identity and verifications models for an overall capability in authentication of personal and sensitive data (like those of the medical files involved). The authentication procedure involves two clear steps. The first one is when data are submitted and collected by the systems. At this step, a plethora of validity tests and/with data available from original sources are performed. The second

step is when authentication is performed among public/local agencies or any other local supervising organization of the service offered, both at citizen's State or enterprise's origin and the State in connection abroad. The European Commission of the European Union has fulfilled the needs on system's legal interoperability by forming the EU Regulation No 910/2014 of the European Parliament and the Council of the European Union on "Electronic identification and trust services for electronic transactions in the internal market (eIDAS Regulation)", therefore, providing the legislative and the regulatory framework for the creation of an appropriate environment, in which citizens, businesses and public administrations can have secure interaction, endorsing and strengthening appropriately the cross-border authentication $[5,6]$.

The regulation also takes into consideration STORK's e-ID Interoperability Framework. The framework comprises of various national nodes acting as Pan-European Proxy Services (PEPS) or Middle Wares (MW Solution) depending on the architectural solution that has been accommodated by the Member States. The overall authentication procedure is the essential part of a reliable, secure and consistent system like the proposed one. It involves 9 steps, starting from access request by the appropriate user and followed by other steps in between until the access to the requested resource gets permission (Figure 2).

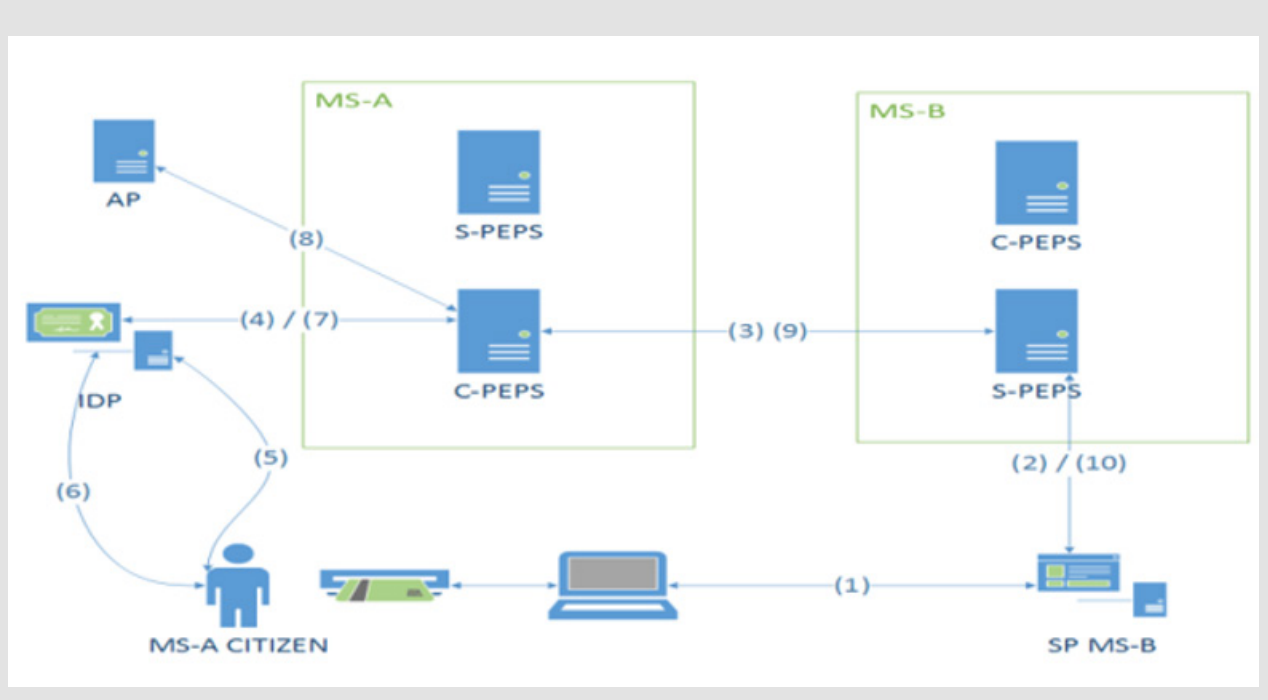

Figure 2: Cross Border Authentication through STORK 2.0 [5].

\section{Discussion}

The proposed Cross Border e-Government system, described here in short, is based to the adoption of eIDAS authentication platform in cross-border transactions and applications. Unfortunately, a serious obstacle for the deployment of such systems is still the lack of reliable implementation of eIDAS nodes by all EU Member States. An additional problem in extensive use of eIDAS authentication is the inadequate number of attributes reinforced by eIDAS regulation. This limitation forces the EU Member States and the application developers to embrace definite solutions to overcome the absence of the preferred attributes. Practically, the use of eIDAS authentication increases the overall user experience and enhances system security. In recent publications, the service described in short here seem to be supported by a "dream like" system [2]. Even during the implementation of its first step (phase 1 , automation of services provided by a typical Primary Health
Care centre) an infinite number of criteria needed to be fulfilled. Although nearly fifty years on medical files research have passed, a lot of problems remain unsolved regarding this attribute of our system. Nevertheless, and in spite of the difficulties involved, research should more emphatically directed towards the full implementation of systems similar to the proposed one since medical community needs it and citizen's life, in many cases, may be saved.

\section{References}

1. Sideridis AB, Protopappas L, Tsiafoulis S, Pimenidis E (2015) Smart Cross-Border e-Gov Systems and Applications. In: Proceedings of the 6th E-Democracy Conference 151-168.

2. Sideridis AB, Pimenidis E, Costopoulou K, Yialouris CP, Savvas I, et al. (2017) e-Gov: Recent Advances in Life Sciences \& EE's Project Proposals (Medical, Animal, Plant, Food Sciences and Environmental Protection), Doctoral Consortium, HAICTA 2017. Chania, Crete (2017b).

3. (2016) STORK 2.0 eID Consortium, D4.3 First Version of Technical Design. 
4. (2016) STORK 2.0.

5. (2014) European Parliament and the Council of the European Union.: Regulation (EU) No 910/2014 on electronic identification and trust services for electronic transactions in the internal market and repealing Directive 1999/93/EC 27. In: Official Journal of the European Union, L 257/73, Brussels (2014).

\section{ISSN: 2574-1241}

DOI: 10.26717/BJSTR.2021.33.005408

Alexander B Sideridis. Biomed J Sci \& Tech Res

(C) $\bigodot_{\text {BY }}^{\text {This work is licensed under Creative }}$

Submission Link: https://biomedres.us/submit-manuscript.php
6. (2017) European Union: Directive 2011/24/EU of the European Parliament and of the Council on the application of patients' rights in cross-border healthcare.

$\begin{array}{ll}\text { BIOMEDICAL } & \text { Assets of Publishing with us } \\ \text { RESEARCHES } & \text { - Global archiving of articles } \\ \text { - Immediate, unrestricted online access } & \text { - Rigorous Peer Review Process } \\ & \text { - Authors Retain Copyrights }\end{array}$

